\title{
APLICAÇÃO DE MÉTODO DE ANÁLISE DE RISCO VISANDO O APRIMORAMENTO DA SEGURANÇA CONTRA INCÊNDIO NO DECORRER DO PROCESSO DE PROJETO DE HOSPITAIS DE GRANDE PORTE
}

\author{
Application of Risk Analysis Method of Targeting the \\ Improvement of Fire Safety During the Design \\ Process for Hospitals Buildings
}

\section{Adriana Galhano Venezia', Rosária Ono'}

\begin{abstract}
RESUMO O presente trabalho discute formas de estabelecer um nível de risco de incêndio adequado a edificações hospitalares de grande complexidade. Com base no Método de Mosler desenvolveu-se um método específico para identificar e classificar o risco de incêndio na edificação hospitalar. O método baseou-se na metodologia de análise de risco qualitativa e em técnicas de gestão de risco corporativo. O trabalho resultou no Método de Avaliação de Risco Incêndio Hospitalar (MARIH), concebido para atuar como uma ferramenta para o desenvolvimento do projeto, com vistas a elevar o nível de segurança contra incêndio nas edificações hospitalares. Além disso, pretendeu-se, com o uso dessa ferramenta, demonstrar aos projetistas e empreendedores a importância da inserção adequada e da integração da segurança contra incêndio no processo de projeto de edificações de grande porte e complexas.
\end{abstract}

PALAVRAS-CHAVE Segurança contra incêndio, análise de risco, edifício hospitalar, códigos prescritivo.

\begin{abstract}
This paper discusses ways to establish a suitable level of fire risk for hospital buildings of great complexity. Based on Mosler Method, a specific method for identifying and classifying fire risk in hospital buildings was developed. The method was called MARIH, Hospital Fire Risk Assessment Method, and used qualitative risk analysis methodology and corporate risk management techniques. MARIH was meant to be a tool in the development of the building project, aiming to raise the level of fire safety in hospital buildings. Moreover, this paper aimed to show designers and entrepreneurs, through MARIH, the importance of proper insertion and integration of fire safety in the design process of large complex buildings.
\end{abstract}

KEYWORDS Fire safety, risk analysis, health care facilities, prescriptive codes.
How to cite this article:

VENEZIA A. G.; ONO, R. Aplicação de método de análise de risco visando o aprimoramento da segurança contra incêndio no decorrer do processo de projeto de hospitais de grande porte. Gestão de Tecnologia de Projetos, São Paulo, v. 8, n. 2, p. 89-103, jul./dez. 2013. http://dx.doi.org/10.11606/gtp.v8i2.68274
Fonte de financiamento: Declaram não haver.

Conflito de interesse: Declaram não haver.

Submetido em: 19 ago., 2013 Aceito em: 04 dez., 2013 


\section{INTRODUÇÃO}

Os hospitais tornaram-se, nos últimos tempos, edifícios que abrigam, além dos doentes, uma infinidade de tratamentos médicos que incluem aparelhagem específica e atividades ligadas à pesquisa e ao ensino. Para conseguir oferecer tais serviços, torna-se necessária uma estrutura física compatível à complexidade inerente. A constante transformação espacial que este espaço sofre, em função de novos conhecimentos médicos e novas tecnologias acabam por modificar, a todo momento, o ambiente construído.

A complexidade do projeto hospitalar também pode ser compreendida sob o enfoque do extenso programa de necessidades combinado com parâmetros funcionais rigorosos, múltiplas redes de instalações prediais, e a necessidade de flexibilidade construtiva para que se possa incorporar novas tecnologias médicas. Além disso, o edifício hospitalar comporta equipamentos sofisticados que exigem instalações complexas.

No tocante ao processo de projeto de um edifício hospitalar, as fases equivalem às de qualquer outro projeto de grande porte, a saber: estudo preliminar, anteprojeto, projeto de prefeitura, projeto executivo, detalhamento, entre outras. Qualquer projeto de uma edificação de grande porte envolve equipes multidisciplinares, planejamento e elaboração de cronogramas físico-financeiros mais complexos.

O diferencial do projeto do edifício hospitalar refere-se ao ciclo de vida útil do edifício, pois o edifício está em constante adaptação devido à evolução das tecnologias médicas, aos novos usos do espaço e às necessidades dos pacientes.

Ao se conceber o projeto hospitalar, além de todas as questões já conhecidas de projeto, tais como segurança estrutural, conforto térmico, conforto acústico, conforto lumínico, estanqueidade, funcionalidade e acessibilidade, dentre outras, é necessário pensar especificamente sob a perspectiva da segurança contra incêndio ou do risco da ocorrência de um incêndio.

Um evento dessa natureza em um centro cirúrgico ou próximo a uma unidade de terapia intensiva pode ser fatal para os pacientes e funcionários e as perdas materiais envolvidas podem vir a inviabilizar o funcionamento das atividades por um longo período.

A segurança contra incêndio deve também acompanhar as modificações ocorridas no decorrer da vida útil de um hospital, sempre proporcionando o nível de segurança projetado de acordo com a previsão de risco de incêndio esperado.

\section{AS LEGISLAÇÕES E O PROJETO HOSPITALAR}

$\mathrm{Na}$ maioria dos casos, no que se refere a projetos hospitalares, a segurança contra incêndio é tratada pelos projetistas como uma obrigação legal ou cartorial a ser cumprida, sem que haja o questionamento do nível de segurança mais apropriado para a edificação em questão, baseando-se apenas nos parâmetros que a legislação impõe.

Qualquer edifício hospitalar a ser edificado no município de São Paulo, no que se refere à segurança contra incêndio, deve atender ao Código de Obras e Edificações do Município de São Paulo - COE (SÃO PAULO, 1992) -, o Decreto Estadual 56.819/2011 (SÃO PAULO, 2011) do Corpo de Bombeiros do Estado de São Paulo (que substitui o Decreto Estadual 46.076/2001), e a RDC №50 - Normas para Projetos Físicos de Estabelecimentos Assistenciais de Saúde da Agência Nacional de Vigilância Sanitária - ANVISA (2002). 
O estudo de tais regulamentações propicia o entendimento dos requisitos para a obtenção do nível de segurança contra incêndio de uma edificação hospitalar, do ponto de vista legal. No entanto, há o grave problema de algumas dessas leis, que devem ser cumpridas, estarem desatualizadas ou, em muitos casos, apresentarem divergências de conteúdo e requisitos entre si. Tudo isso irá refletir no nível de segurança contra incêndio projetado para a edificação hospitalar.

Deve-se, então, considerar que devido à complexidade do edifício hospitalar de grande porte, as legislações que fornecem os parâmetros para a obtenção do nível de segurança exigido ao risco podem não ser suficientes para um projeto seguro contra incêndios.

\section{OBJETIVO}

Este trabalho tem como objetivo apresentar um método de análise de risco qualitativo que propicie um nível de segurança contra incêndio adequado ao risco esperado em uma edificação hospitalar de grande porte, visto que o estrito atendimento às exigências de códigos e regulamentações prescritivas podem não garantir um adequado nível de segurança contra incêndio.

O método MARIH (VENEZIA, 2012) foi concebido para atuar como uma ferramenta para o desenvolvimento do projeto, com vistas a elevar o nível de segurança contra incêndio nas edificações hospitalares. Além disso, pretendese, com o uso dessa ferramenta, demonstrar aos projetistas e empreendedores a importância da inserção adequada e da integração da segurança contra incêndio no processo de projeto de edificações de grande porte e complexas.

\section{METODOLOGIA}

No caso específico deste trabalho, realizou-se uma pesquisa exploratória baseada em técnicas qualitativas. Infelizmente, no Brasil, há um grave problema de falta de dados estatísticos sobre incêndios de toda a natureza, inclusive incêndios hospitalares. Não há um órgão responsável pela coleta e registro de forma padronizada desses dados no âmbito nacional. Muitos dos Corpos de Bombeiros Estaduais apenas realizam esses registros para seu uso interno. Portanto, no país não há uma base nacional de dados disponível para aplicação em pesquisas.

Assim sendo, frente à precariedade de dados de incêndio encontrada no Brasil, decidiu-se, para o desenvolvimento da análise de risco neste trabalho, explorar métodos de avaliação qualitativos que se baseiam em técnicas de gestão de risco corporativo. Especificamente, o Método de Mosler foi o escolhido, após levantamento e análise de vários métodos, pois ele é o que melhor se adapta, com os devidos ajustes, à avaliação de edificações hospitalares do ponto de vista da segurança contra incêndio.

O Método de Mosler é uma forma de gestão de riscos corporativos que acompanha a evolução dos riscos de maneira geral. É um método subjetivo e, portanto, deve ser utilizado quando não há banco de dados históricos disponíveis e confiáveis que possam ser matematicamente empregados.

Este Método depende da experiência do avaliador, pois cabe a ele a função de atribuir a pontuação para avaliar os critérios utilizados no método. Portanto, o resultado encontrado pode variar em função da perícia e do conhecimento do avaliador. Para classificar os riscos, o Método de Mosler possui seis critérios, a saber: 
- Critério da função - "F”. Este critério projeta as conseqüências negativas ou danos que podem alterar a atividade principal da empresa ou organização;

- Critério da substituição - "S". Este critério avalia qual o impacto da concretização da ameaça sobre os bens, ou seja, o quanto os bens atingidos podem ser substituídos;

- Critério da Profundidade - "P”. Este critério mede a perturbação e os efeitos psicológicos, uma vez materializado o risco, que o risco poderá causar para a imagem da empresa ou da organização;

- Critério da Extensão - “E”. Este critério mede o alcance e a extensão que o dano pode causar à empresa ou organização;

- Critério da Probabilidade - "Pb". Este critério mede a possibilidade do dano ou risco vir a acontecer, tendo em vista as características conjunturais e físicas da empresa ou organização;

- Critério da Vulnerabilidade - "V". Este critério mede quais serão as perdas causadas pela concretização do risco no âmbito financeiro.

O objetivo é a obtenção da Evolução do Risco (ER), que é o produto dos fatores Magnitude (M) e Perda Esperada (Pe). A Magnitude (M) depende dos fatores Importância do sucesso (I) e Danos causados (D). E a Perda Esperada (Pe), por sua vez, depende dos critérios de Probabilidade ( $\mathrm{Pb}$ ) e Vulnerabilidade (V).

Com base no Método de Mosler desenvolveu-se um método específico para identificar e classificar o risco de incêndio na edificação hospitalar. $O$ método desenvolvido permite avaliar as conseqüências da ocorrência do incêndio sob os pontos de vista da paralisação das atividades hospitalares, da substituição dos bens atingidos, dos efeitos negativos à imagem da instituição, do tempo de interrupção das atividades, das perdas financeiras e da possibilidade de salvamento dos ocupantes da edificação hospitalar.

Para uma melhor estruturação do método proposto, chamado de Método de Avaliação de Risco Incêndio Hospitalar (MARIH), método esse que visa, inicialmente, a identificação dos riscos de incêndio na edificação hospitalar de grande porte e, posteriormente, a análise da possibilidade de ocorrência do incêndio, decidiu-se trabalhar com as áreas definidas na listagem dos ambientes próprios para Estabelecimentos Assistenciais de Saúde, encontrada na RDC N50 da ANVISA (AGÊNCIA..., 2002), que classifica e nomeia todas as atividades desenvolvidas em hospitais gerais de grande porte.

A partir da listagem dessas áreas hospitalares, realizou-se uma avaliação dos riscos relacionados à possibilidade de ocorrência de um incêndio e das conseqüências da ocorrência desse incêndio. Nessa avaliação, é proposto um sistema de atribuição de pontuação ajustado para o tipo de atividade desenvolvida em cada ambiente listado na RDC N50 da ANVISA.

\section{MÉTODO DE AVALIAÇÃO DE RISCO INCÊNDIO HOSPITALAR (MARIH)}

O Método de Avaliação de Risco Incêndio Hospitalar (MARIH) utiliza dez critérios para classificar o risco:

- Critério função (Fn) - projeta as conseqüências de um incêndio que interferem na atividade principal da organização, ou seja, na normalidade das rotinas desenvolvidas no local;

- Critério substituição (Sb) - avalia qual o impacto do incêndio sobre os bens materiais, ou seja, com que nível de dificuldade o conteúdo atingido pode ser substituído; 
- Critério profundidade (Pf) - avalia a perturbação sensitiva dos ocupantes, uma vez materializado o risco, no local do risco e o impacto que o incêndio pode causar à imagem da organização;

- Critério extensão (Ex) - avalia o alcance e a extensão que o dano pode vir a causar ao local analisado e suas áreas interdependentes, em razão do tempo de paralisação da atividade principal da área analisada;

- Critério carga incêndio (Ci) - avalia a quantidade de material combustível encontrada na área analisada;

- Critério vulnerabilidade (Vu) - avalia as perdas causadas pela consolidação do incêndio no âmbito financeiro, considerando perdas de equipamentos, insumos e o custo da paralisação das atividades desenvolvidas na área analisada;

- Critério sobrevivência local (Sv) - avalia a possibilidade dos ocupantes da área analisada abandonarem o local sem grandes prejuízos à sua integridade física;

- Critério sobrevivência externa (Sx) - avalia a facilidade dos ocupantes das demais áreas da edificação hospitalar, que não a área propriamente analisada, abandonar a edificação sem grandes prejuízos à sua integridade física;

- Critério probabilidade intrínseca (Pi) - avalia a possibilidade do incêndio vir a acontecer, tendo em vista as características físicas e conjunturais da área analisada da edificação hospitalar;

- Critério probabilidade externa (Px) - avalia o risco de incêndio de origem externa, tendo em vista as características físicas e conjunturais do entorno do hospital.

Para cada área hospitalar são atribuídos em cada um desses critérios valores que variam dentro da pontuação de 1 a 5 . É importante esclarecer que o método aqui proposto é um método qualitativo, que depende do conhecimento e experiência do avaliador. Em virtude disso, o Método de Avaliação de Risco Incêndio Hospitalar (MARIH) é melhor aplicado quando os profissionais envolvidos no projeto detêm um bom conhecimento acerca das questões de segurança contra incêndio.

\section{CONCEITOS DO MÉTODO DE AVALIAÇÃO DE RISCO INCÊNDIO HOSPITALAR (MARIH)}

No método proposto, o objetivo final é determinar o índice denominado "Evolução de Risco de Incêndio" - (ERI) - para cada ambiente listado na RDC No50 da ANVISA. Tal índice avalia as consequências dos principais aspectos que podem ocorrer em um incêndio no tocante às perdas de vida, às perdas financeiras, às perdas de bens e à paralisação das atividades.

O índice Evolução de Risco de Incêndio (ERI) é calculado em função dos seguintes valores, a saber: Magnitude (Mg), Perdas Esperadas (Pe), probabilidade intrínseca (Pi) e probabilidade externa (Px). Portanto, é proposto o cálculo do índice Evolução de Risco de Incêndio (ERI) através da função ERI = f(Mg, Pe, Pi, Px),

$$
\mathrm{ERI}=\frac{\left[\mathrm{Mg} \cdot \mathrm{Pe} \cdot\left(\frac{3 \mathrm{Pi}+2 \mathrm{Px}}{5}\right)\right]}{50}
$$

Onde:

- Magnitude (Mg): é a variável que representa a mensuração das perdas que a concretização do incêndio pode causar na organização no tocante à paralisação das atividades do hospital; 
- Perdas Esperadas (Pe): é a variável que representa a mensuração da combinação das perdas financeiras com as perdas humanas que podem ocorrer em um incêndio;

- Probabilidade intrínseca (Pi): é o critério que avalia a possibilidade do incêndio vir a acontecer, tendo em vista as características físicas e conjunturais da área analisada da edificação hospitalar;

- Probabilidade externa (Px): é o critério que avalia o risco de incêndio de origem externa, tendo em vista as características físicas e conjunturais do entorno do hospital.

\section{CÁLCULO DA VARIÁVEL MAGNITUDE}

No Método de Avaliação de Risco Incêndio Hospitalar (MARIH), para o cálculo da variável Magnitude (Mg), primeiramente, propõe-se atribuir a pontuação a 5 critérios. São eles: função (Fn), substituição (Sb), profundidade (Pf), extensão (Ex) e carga incêndio (Ci). Propõe-se, então, calcular a variável Magnitude $(\mathrm{Mg})$ através da função $\mathrm{Mg}=\mathrm{f}(\mathrm{In}, \mathrm{Dc})$, cuja fórmula é:

$$
\mathrm{Mg}=\mathrm{In}+\mathrm{Dc}
$$

Onde: In = intensidade e Dc = danos causados

O valor intensidade (In) pode ser definido como a consequência que um incêndio pode vir a ter no funcionamento e na imagem da organização. Deve-se considerar que o critério função (Fn) tem uma relevância maior do que o critério substituição (Sb) e maior do que o critério profundidade (Pf), pois no critério função (Fn) é avaliada a paralisação da área em relação a sua função dentro da edificação hospitalar. Os critérios substituição (Sb) e profundidade (Pf) avaliam, de certo modo, consequências menores dentro do funcionamento do hospital. Intensidade (In) é calculado, então, pela função In = $\mathrm{f}(\mathrm{Fn}, \mathrm{Sb}, \mathrm{Pf})$, cuja fórmula proposta é:

$$
\mathrm{In}=2 \mathrm{Fn} .(\mathrm{Sb}+0,5 \mathrm{Pf})
$$

Onde: $\mathrm{Fn}$ = função, $\mathrm{Sb}$ = substituição e $\mathrm{Pf}$ = profundidade

O critério função (Fn) foi multiplicado pelo fator 2, pois avalia os danos que interferem no desenvolvimento das atividades hospitalares, sendo o critério de maior importância no cálculo do valor intensidade (In), se comparado aos danos decorrentes da substituição dos bens hospitalares e aos danos causados à imagem do hospital. Ao se comparar o critério substituição (Sb) com o critério profundidade (Pf), percebe-se que o critério substituição (Sb) tem um peso maior do que o critério profundidade (Pf), pois trata do tempo da substituição dos bens. Portanto, o critério profundidade (Pf) é multiplicado pelo fator 0,5 reduzindo seu valor a metade.

O método proposto, o valor danos causados (Dc) avalia a extensão que o incêndio pode causar à edificação, mas restringe-se apenas aos danos físicos. Considera-se, para o cálculo desse valor, o critério extensão (Ex) - avalia o alcance e a extensão do incêndio - e o critério carga incêndio (Ci) - avalia a quantidade de material combustível do local analisado. $\mathrm{O}$ valor danos causados (Dc) é calculado pela função Dc = f(Ex, Ci), cuja fórmula é:

$$
\mathrm{Dc}=\mathrm{Ex} \cdot \mathrm{Ci}
$$

Onde: $\mathrm{Ex}$ = extensão e $\mathrm{Ci}$ = carga incêndio

\section{CRITÉRIOS ESTÁVEIS E NÃO ESTÁVEIS}

No Método de Avaliação de Risco Incêndio Hospitalar (MARIH), propõe-se a divisão dos critérios entre estáveis e não estáveis. Os critérios estáveis são aqueles que possuem pouca ou nenhuma variação na pontuação de uma edificação hospitalar de grande porte para outra similar. Já os critérios não 
estáveis apresentam pontuações que se alteram de uma edificação hospitalar de grande porte para outra, uma vez que são fortemente influenciadas por características particulares de cada edificação.

Assim sendo, no MARIH, os 5 critérios - função (Fn), substituição (Sb), profundidade (Pf), extensão (Ex) e carga incêndio (Ci) - podem ser vistos como critérios estáveis. Eles possuem pouca ou nenhuma variação de uma edificação hospitalar de grande porte para outra similar, uma vez que avaliam a função da área do princípio de incêndio (Fn), o impacto do incêndio sobre os bens materiais (Sb), a perturbação psicológica e o impacto na imagem do hospital em função da área do princípio de incêndio (Pf), o alcance e a extensão do incêndio na área atingida (Ex), e a quantidade de material combustível (Ci) do local do incêndio. A variável Magnitude (Mg) é calculada em função destes critérios, pode-se, então, dizer que a variável Magnitude (Mg) também é estável para as edificações hospitalares de grande porte.

Sabe-se que a variável Magnitude $(\mathrm{Mg})$, definida anteriormente, representa a mensuração das perdas que a concretização do incêndio pode causar na organização no tocante à paralisação das atividades do hospital. As áreas que possuírem a variável Magnitude $(\mathrm{Mg})$ maior tendem a ter o índice Evolução de Risco de Incêndio (ERI) maior. No Método proposto, verificou-se a necessidade de definir faixas da variável Magnitude $(\mathrm{Mg})$ para estabelecer diferentes classes de risco, conforme apresentado no Quadro 1, derivado do Método de Mosler e adaptado para esta situação.

Quadro 1. Classificação das classes de risco da variável Magnitude (Mg) - MARIAH.

Quadro 1. Classificação das classes de risco da variável Magnitude (Mg) - MARIAH.
\begin{tabular}{|c|l|}
\hline Variável Magnitude (Mg) & Classes de Risco \\
\hline de $4-15$ & Risco muito baixo \\
de $16-30$ & Risco baixo \\
de $31-50$ & Risco significativo \\
de $51-70$ & Risco alto \\
de $71-100$ & Risco muito alto \\
\hline
\end{tabular}

\section{CÁLCULO DA VARIÁVEL PERDAS ESPERADAS}

No MARIH, após calcular o valor da variável Magnitude (Mg), é proposto também o cálculo da variável Perdas Esperadas (Pe) que é o produto das perdas financeiras com as perdas humanas no incêndio. A variável Perdas Esperadas (Pe) está diretamente relacionada com as duas grandes perdas que podem ocorrer com a concretização do incêndio: as perdas humanas e as perdas financeiras. Para o cálculo da variável Perdas Esperadas (Pe), é necessária a atribuição da pontuação aos critérios vulnerabilidade (Vu), sobrevivência local (Sv) e sobrevivência externa (Sx).

Na proposição do cálculo da variável Perdas Esperadas (Pe) no MARIH, o conceito de perdas financeiras - critério vulnerabilidade (Vu) - e o conceito de perdas humanas - critério de sobrevivência local (Sv) e sobrevivência externa (Sx) - possuem pesos iguais.

Neste trabalho, adotou-se o pressuposto de que a segurança contra incêndio é desenvolvida com o objetivo maior de proteger os ocupantes. Entretanto, é de igual importância a proteção dos bens materiais para que os prejuízos financeiros sejam os menores possíveis. Tal medida de proteção 
dos bens materiais e, por conseguinte, menores prejuízos financeiros, garante a continuidade do funcionamento da edificação hospitalar e a dos serviços hospitalares e, assim, a do tratamento dos pacientes (especificamente aqueles que não podem ser retirados do edifício). A edificação hospitalar, que tem, em decorrência de um incêndio, perdas financeiras muito grandes, dificilmente consegue manter as atividades de prestação de atendimento imediato de assistência à saúde e a prestação de atendimento de apoio ao diagnóstico e terapia, que são suas funções principais. Em outras palavras, a ausência do hospital e da aparelhagem médica pode resultar na morte de indivíduos. Desse ponto de vista, salvar o edifício, com menor prejuízo financeiro possível é salvar vidas. Por isso, pesos iguais foram atribuídos às perdas humanas e às perdas financeiras.

As perdas financeiras correspondem ao critério vulnerabilidade (Vu). As perdas humanas correspondem a dois critérios: sobrevivência local (Sv) e sobrevivência externa (Sx). Propõe-se, então, calcular a variável Perdas Esperadas $(\mathrm{Pe})$ através da função $\mathrm{Pe}=\mathrm{f}(\mathrm{Vu}, \mathrm{Sv}, \mathrm{Sx})$, cuja fórmula é:

$$
\mathrm{Pe}=2 .(5 \mathrm{Vu}+2 \mathrm{~Sv}+3 \mathrm{Sx})
$$

Onde: $\mathrm{Vu}$ = vulnerabilidade, $\mathrm{Sl}$ = sobrevivência local e $\mathrm{Sx}$ = sobrevivência externa

A soma dos pesos dos critérios sobrevivência local (Sv) e sobrevivência externa (Sx), que são respectivamente 2 e 3, é igual ao peso do critério vulnerabilidade (Vu) que é 5 . O valor da soma dos três critérios - vulnerabilidade $(\mathrm{Vu})$, sobrevivência local (Sv) e sobrevivência externa (Sx) - é, ainda, multiplicado pelo fator 2, para se ter uma escala de resultados da variável Perdas Esperadas (Pe) variando de 20 a 100. Tal multiplicação é feita com 0 intuito de facilitar a fórmula de cálculo da variável Perdas Esperadas (Pe). Dessa forma, a escala de resultados passa a ser compatível com a escala de resultados da variável Magnitude (Mg) encontrada na Tabela 5.1. Os 3 critérios usados no cálculo da variável Perdas Esperadas - Vulnerabilidade (Vu), Sobrevivência Local (Sv) e Sobrevivência Externa (Sx) - podem ser vistos como critérios não estáveis, pois apresentam pontuações alteráveis de uma edificação hospitalar de grande porte para outra similar.

Pode-se dizer, então, que a variável Perdas Esperadas (Pe) apresenta um valor não estável para as edificações hospitalares de grande porte, ao se comparar uma edificação a outra similar, pois para o seu cálculo é necessário levar em consideração as características físicas específicas da edificação em questão.

\section{CÁLCULO DO ÍNDICE EVOLUÇÃO DE RISCO DE INCÊNDIO (ERI)}

A probabilidade de ocorrência de incêndio tem influência direta no resultado do índice ERI, juntamente com as consequências da concretização do incêndio para a edificação hospitalar.

Todavia, os critérios de probabilidade possuem pesos diferentes, uma vez que um incêndio no interior da edificação hospitalar - critério probabilidade intrínseca (Pi) - pode vir a ter consequências mais graves do que um incêndio que se inicie nas adjacências da edificação hospitalar - critério probabilidade externa (Px). Portanto, o critério de probabilidade intrínseca (Pi) possui um peso maior que o critério probabilidade externa (Px). Assim, no método proposto, para o cálculo do índice ER), tem-se a multiplicação da variável Magnitude (Mg) pela variável Perdas Esperadas (Pe) que, por sua vez, é multiplicado pela média ponderada entre o critério probabilidade intrínseca (Pi) e o critério probabilidade externa (Px). 
Atribui-se ao critério probabilidade intrínseca ( $\mathrm{Pi}$ ) um peso maior, e portanto, para fins de cálculo, ele é multiplicado por 3, já o critério probabilidade externa (Pe), que possui peso menor, é multiplicado por 2. A soma desses dois valores ainda é dividida pelo fator 5 , o que caracteriza uma média ponderada entre os critérios de probabilidade externa e probabilidade intrínseca.

O resultado encontrado nessa multiplicação é, então, dividido pelo fator 50 para que o valor do índice ERI seja classificado na escala de risco em uma faixa que varia de 2 a 1000. A divisão dessa multiplicação pelo fator 50 foi, de fato, um ajuste de escala já que o valor encontrado sem esta divisão seria de difícil visualização.

Após o cálculo do ERI, tal índice é classificado em uma classe de risco. Para a criação da tabela de classe de risco para o ERI, foram adotadas as mesmas definições de risco utilizadas no Método de Mosler, que são: risco reduzido, risco importante, risco elevado, risco crítico e risco desastroso. Porém, a divisão dos valores em patamares em cada de classe de risco é diferente.

O método proposto utiliza a escala de risco nos valores de 2 a 1000, divididos em 5 partes, porém em faixas variáveis. O risco reduzido compreende a faixa de valor de 2 a 50 , o risco importante estabelece a faixa de 51 a 150, já o risco elevado fica entre 151 a 400, o risco crítico estabelece os valores de 401 a 700 e, finalmente, o risco desastroso fica entre 701 a 1000. Essa variação mostrou-se ser a mais adequada na classificação do índice Evolução de Risco de Incêndio (ERI), pois aumenta a margem de segurança na edificação uma vez que os patamares de risco crítico e risco desastroso são ampliados.

Para determinar a calibração das faixas das classes de risco do índice ERI, primeiramente atribui-se a pontuação 1 a todos os dez critérios chegando-se ao valor do ERI. Realizou-se, então, esse processo novamente, atribuindo-se a pontuação 2 a todos os dez critérios chegando-se ao valor ERI. Tal processo foi repetido com as pontuações 3,4 e 5 . Os valores de ERI encontrados para as pontuações 1, 2, 3, 4 e 5 dada aos dez critérios foram 2, 26, 78, 410, 1000 respectivamente. De posse desses resultados, percebeu-se que as faixas deveriam ser calibradas para que houvesse coerência na classificação do ERI com o valor obtido pela fórmula.

Foi proposta, inicialmente, uma divisão de valores que diminuía o patamar de risco reduzido e o patamar de risco importante, e ampliava o patamar de risco crítico e o patamar de risco desastroso. A seguir, aplicou-se a fórmula de ERI em um projeto de edificação hospitalar de grande porte edificado no município de São Paulo, em todos os seus ambientes. De posse de todos os resultados de ERI, após uma análise dos resultados, a calibração foi corrigida. Tal calibração se mostrou a mais adequada para ilustrar as perdas que podem ocorrer em função do aumento do índice ERI.

No MARIH, de posse das duas variáveis, Magnitude (Mg) e Perdas Esperadas (Pe), juntamente com os critérios probabilidade intrínseca (Pi) e probabilidade externa (Px), calcula-se o índice Evolução de Risco de Incêndio (ERI). Portanto, é proposto o cálculo do ERI através da função ERI = f (Mg, Pe, Pi, Px) pela seguinte equação:

$$
\text { ERI }=\frac{\left[\mathrm{Mg} \cdot \mathrm{Pe} \cdot\left(\frac{3 \mathrm{Pi}+2 \mathrm{Px}}{5}\right)\right]}{50}
$$

Onde: $\mathrm{Mg}=$ Magnitude, $\mathrm{Pe}=$ Perdas Esperadas, $\mathrm{Pi}=$ probabilidade intrínseca e $\mathrm{Px}=$ probabilidade externa 
Os resultados encontrados para o índice Evolução de Risco de Incêndio (ERI) que não forem números inteiros devem automaticamente ser arredondados para o próximo número inteiro, imediatamente superior. De posse do índice Evolução de Risco de Incêndio (ERI), propõe-se classificá-lo em classes de risco apresentado no Quadro 2.

Quadro 2. Classificação do índice Evolução de Risco de Incêndio (ERI) segundo a classe de risco.

\begin{tabular}{|c|c|c|}
\hline Índice - ERI & Classe de Risco & Definição \\
\hline de 2 a 50 & Reduzido & $\begin{array}{l}\text { A possibilidade de ocorrência de um incêndio no ambiente considerado } \\
\text { é muito baixa. E, no caso de ocorrer um incêndio nessa área, tal evento } \\
\text { ocasiona muito pouco transtorno ao hospital no que se refere à paralisação } \\
\text { de atividades, e prejuízos financeiros, entre outras ocorrências. Não há } \\
\text { danos físicos aos ocupantes da edificação. }\end{array}$ \\
\hline de 51 a 150 & Importante & $\begin{array}{l}\text { A possibilidade de ocorrência de um incêndio no ambiente considerado é } \\
\text { baixa. E, no caso de ocorrer um incêndio nessa área, tal evento ocasiona } \\
\text { pouco transtorno às atividades do hospital. As áreas atingidas podem } \\
\text { transferir suas atividades para outros locais, com poucas perturbações no } \\
\text { funcionamento do hospital. Os prejuízos financeiros são restritos às áreas } \\
\text { atingidas sem perdas de equipamentos eletro-médicos ou equipamentos de } \\
\text { infra-estrutura. Também não há danos físicos aos ocupantes da edificação. }\end{array}$ \\
\hline de 151 a 400 & Elevado & $\begin{array}{l}\text { Um incêndio no ambiente considerado pode provocar a paralisação de } \\
\text { alguns setores do hospital. A remoção de pacientes críticos será feita no } \\
\text { mesmo pavimento, para áreas adjacentes ao seu local de tratamento. Há } \\
\text { possibilidade remota de perda de vidas humanas. Os prejuízos financeiros } \\
\text { podem ser altos. }\end{array}$ \\
\hline de 401 a 700 & Crítico & $\begin{array}{l}\text { Um incêndio no ambiente considerado pode provocar a paralisação de } \\
\text { parte do hospital. Há a necessidade dos ocupantes deixarem o hospital, } \\
\text { assim como dos pacientes deixarem seu local de tratamento. Há a } \\
\text { possibilidade de perda de vidas humanas, e podem ocorrer grandes } \\
\text { prejuízos financeiros. No nível crítico, o incêndio não se alastra a } \\
\text { propriedades vizinhas. }\end{array}$ \\
\hline de 701 a 1000 & Desastroso & $\begin{array}{l}\text { Um incêndio no ambiente considerado pode provocar a paralisação } \\
\text { das atividades do hospital, perda de vidas humanas, grandes prejuízos } \\
\text { financeiros, possibilidade do fogo se alastrar para propriedades adjacentes, } \\
\text { entre outras catástrofes. }\end{array}$ \\
\hline
\end{tabular}

Retomando-se as questões dos critérios estáveis e não estáveis, os critérios probabilidade intrínseca ( $\mathrm{Pi}$ ) e probabilidade externa (Pe), usados para o cálculo do ERI, podem ser vistos como critérios que apresentam pontuações diferentes de uma edificação hospitalar de grande porte para outra similar. São, portanto, critérios não estáveis. O ERI indica o grau de destruição que o incêndio pode atingir na edificação hospitalar. Portanto, as áreas que obtiverem um índice maior deverão receber tratamento prioritário, pois se considera que em tais áreas o risco de ocorrência de um incêndio seja maior e/ou suas consequências, mais desastrosas. O MARIH foi organizado conforme a estrutura apresentada no Quadro 3 que segue.

\section{APLICAÇÃO DO MÉTODO DE AVALIAÇÃO DE RISCO INCÊNDIO HOSPITALAR (MARIH) NO PROCESSO DE PROJETO}

Neste trabalho é adotado o Manual de Escopo de Projetos e Serviços de Arquitetura e Urbanismo (ASSOCIAÇÃO..., 2010), que tem como principal 
Quadro 3. Método de Avaliação de Risco Incêndio Hospitalar (MARIH).

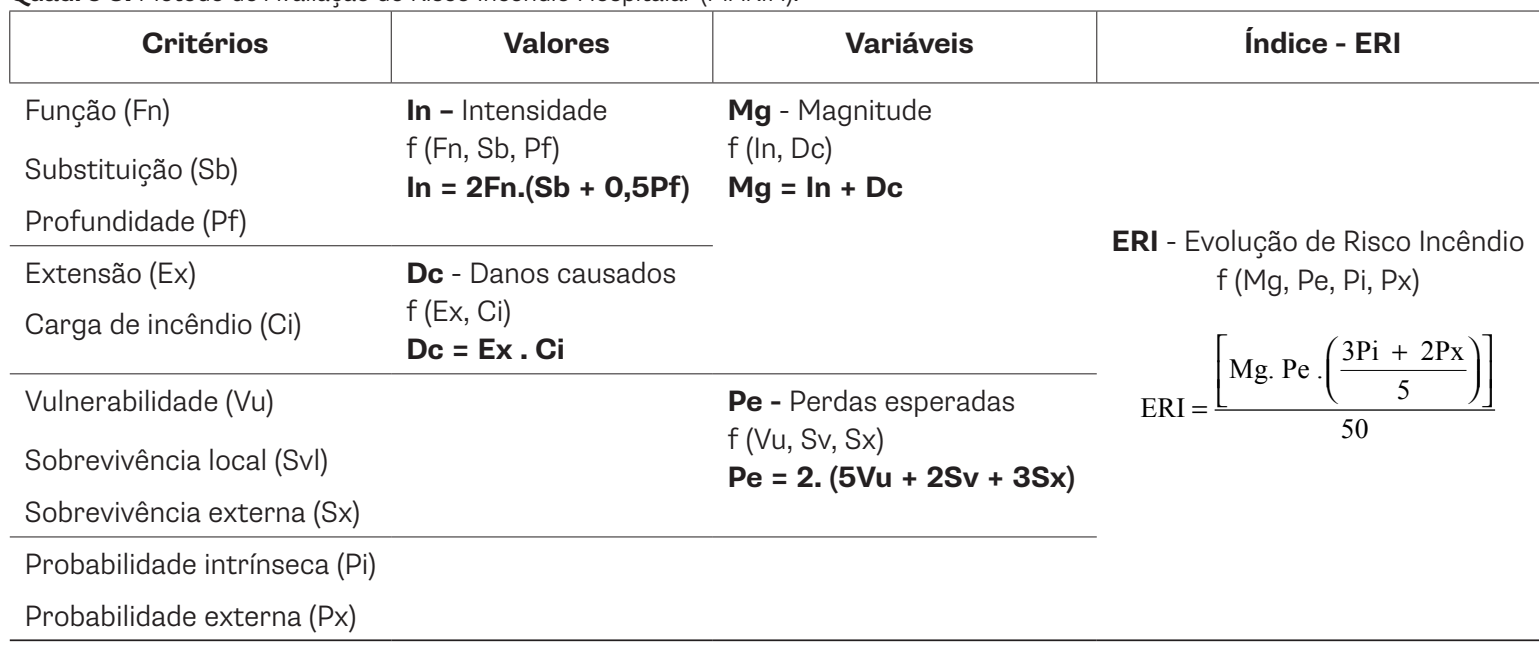

objetivo definir e detalhar o fluxo de atividades das etapas do processo de projeto, criando-se um sistema padronizado que deve ser adaptado às necessidades de cada empreendimento.

A estrutura geral do Manual foi desenvolvida com base na norma ABNT NBR 13.531 - "Elaboração de projetos de edificações - Atividades técnicas" (ASSOCIAÇÃO..., 1995).

O Manual de Escopo de Projetos e Serviços de Arquitetura e Urbanismo é, neste trabalho, adaptado para edificações hospitalares de grande porte, sendo o foco a aplicação do Método de Avaliação de Risco Incêndio Hospitalar (MARIH), ou seja, o desenvolvimento do projeto de segurança contra incêndio adequada às edificações hospitalares de grande porte.

O Quadro 4 apresenta as fases propostas pelo Manual de Escopo de Projetos e Serviços de Arquitetura e Urbanismo (ASSOCIAÇÃO..., 2010) e as ações de segurança contra incêndio que devem ser tomadas em cada fase juntamente com a aplicação do Método de Avaliação de Risco Incêndio Hospitalar (MARIH).

Quadro 4. Aplicação do MARIH e ações de segurança contra incêndio nas fases do processo de projeto (manual de escopo de projetos e serviços de arquitetura e urbanismo).

projetos e serviços de arquitetura eurbanismo).

(Manual de Escopo de Projetos e Serviços de Arquitetura e Urbanismo)

\begin{tabular}{|c|c|c|}
\hline \multirow{5}{*}{$\begin{array}{c}\text { Fase } \\
\text { A - Concepção do } \\
\text { Produto }\end{array}$} & $\begin{array}{l}\text { Levantamento de } \\
\text { dados }\end{array}$ & $\begin{array}{l}\text { Levantamento das exigências contidas nas legislações de } \\
\text { segurança contra incêndio. } \\
\text { Levantamento da existência de limitação no atendimento de } \\
\text { alguma exigência da legislação. }\end{array}$ \\
\hline & $\begin{array}{l}\text { Programa de } \\
\text { Necessidades }\end{array}$ & $\begin{array}{l}\text { Proposta de adoção dos ambientes listados na RDC № } 50 \text { da } \\
\text { ANVISA. }\end{array}$ \\
\hline & \multirow{3}{*}{$\begin{array}{l}\text { Estudo de } \\
\text { Viabilidade }\end{array}$} & $\begin{array}{l}\text { Definição do nível de segurança pretendido para a edificação } \\
\text { hospitalar. }\end{array}$ \\
\hline & & $\begin{array}{l}\text { Discussão da localização dos setores e ambientes da edificação } \\
\text { sob o ponto de vista da segurança contra incêndio. }\end{array}$ \\
\hline & & $\begin{array}{l}\text { Desenvolvimento do esboço de um eixo de compartimentação } \\
\text { horizontal que deve ser seguido em todos os andares. }\end{array}$ \\
\hline
\end{tabular}

\section{Aplicação do MARIH e ações de segurança contra incêndio}

horizontal que deve ser seguido em todos os andares. 
Quadro 4. Continuação...

Fases do processo de projeto

(Manual de Escopo de Projetos e Serviços de Arquitetura e Urbanismo)
Estudo Preliminar

\section{Fase B - Definição do Produto}

Aplicação do MARIH e ações de segurança contra incêndio

Consolidação do potencial construtivo: número total de leitos, de áreas técnicas, de áreas de diagnóstico, entre outras áreas. Proposta de implantação da edificação: organização do fluxo de pessoas, veículos e usos.

Estabelecimento das rotas de fuga, das rotas de entrada para as equipes do corpo de bombeiros e do local para aproximação e estacionamento da viatura do corpo de bombeiros.

Finalização da proposta de projeto preliminar.

Aplicação do Método de Avaliação de Risco Incêndio Hospitalar (MARIH).

Verificação se há alguma exigência prescritiva que não pode ser atendida - a aplicação do MARIH deve refletir as situações críticas do ponto de vista da segurança contra incêndio.

Avaliação dos ambientes segundo o índice de Evolução de Risco de Incêndio (ERI) - atenção especial deve ser dada aos ambientes que obtiverem ERI crítico ou desastroso.

Reelaboração do projeto, se necessário, considerando os índices ERI dos ambientes do projeto.

Desenvolvimento do projeto preliminar em cortes e fachadas.

Definição do eixo de compartimentação horizontal e das áreas a serem compartimentadas.

Análise das condições a serem atendidas pelos elementos estruturais e de vedação para que, no caso de incêndio, não haja um rápido alastramento ou um colapso estrutural.

Estudo dos materiais de revestimento e acabamento sob o ponto de vista da segurança contra incêndio.

Análise das interferências entre os projetos gerados nesta fase.

Projeto Legal

Elaboração da documentação gráfica do projeto legal e dos memoriais.

Consolidação dos projetos propostos na fase B considerando as

Fase

C - Identificação

e Solução de

Interfaces questões de segurança contra incêndio e a aplicação do MARIH; Compatibilização das interferências entre os projetos gerados nesta fase.

Especificação das medidas de proteção passiva e proteção ativa, principalmente dos ambientes que obtiveram os maiores índices ERI. As soluções de segurança contra incêndio devem contemplar os sistemas de revestimento de pisos, vedações

de Detalhamentos

e Especialidades e forros, sistemas de estruturas, sistemas prediais elétricos e hidráulicos, sistemas de climatização, sistemas de automação, sistemas gerais de vedação, sistemas de transportes verticais e projeto de arquitetura de interiores.

Projeto de Execução

Análise e verificação da plena compreensão e utilização das informações contidas nos projetos.
Fase E - Pós-

Entrega do

Projeto

Fase F - Pós-

Entrega da Obra
Análise e verificação do comportamento da edificação em uso para reafirmar se os condicionantes dos projetos foram adequados. 
Na fase A - Concepção do Produto, é fundamental que seja definido o nível de segurança pretendido para a edificação hospitalar. A decisão do nível de segurança irá impactar na discussão dos setores e ambientações da edificação, bem como na localização do eixo de compartimentação que deverá ser seguidos em todos os pavimentos.

Na fase B - Definição do Produto, deve-se desenvolver o partido arquitetônico e demais elementos da edificação hospitalar considerando o nível de segurança contra incêndio, definido na fase A, que se quer obter na edificação hospitalar. Deve-se, também, definir e consolidar todas as informações necessárias a fim de verificar sua viabilidade física, legal e econômica bem como possibilitar a elaboração dos projetos legais.

Na fase C - Identificação e solução de interfaces, deve-se consolidar claramente todos os ambientes nos seus devidos pavimentos, considerando o eixo de compartimentação horizontal e vertical, definidos na fase anterior, suas articulações e demais elementos da edificação hospitalar, fornecendo as definições necessárias para o intercâmbio entre todos os envolvidos no processo.

Na fase D - Projeto de detalhamento das especialidades, deve-se executar o detalhamento de todos os elementos do empreendimento de modo a gerar um conjunto de referências suficientes para a perfeita caracterização das obras/serviços a serem executadas, bem como para a avaliação dos custos, métodos construtivos, e prazos de execução.

Os ambientes que obtiveram os maiores índices ERI devem, nesta fase, ter especificadas as medidas de proteção ativa e as medidas de proteção passiva, considerando o risco envolvido. Tais medidas de proteção devem ser discutidas com os especialistas da área de segurança contra incêndio para que sejam desenvolvidas as melhores soluções possíveis de acordo com o orçamento disponível, tendo como base as diretrizes adotadas desde o início do projeto.

Na fase E - Pós-Entrega do Projeto, deve-se garantir o pleno entendimento e utilização das informações de projeto, assim como sua correta aplicação nos trabalhos de campo.

Na Fase F - Pós-Entrega da Obra, deve-se análisar e avaliar o comportamento da edificação em uso para verificar e reafirmar se os condicionantes e pressupostos de projeto foram adequados.

As fases A, B, C e D possuem relação direta com a aplicação do Método de Avaliação de Risco Incêndio Hospitalar (MARIH), pois são as fases nas quais é estabelecido o nível de risco adequado à edificação e a concepção e o projeto de segurança contra incêndio são desenvolvidos.

\section{CONCLUSÃO}

Espera -se que, com a utilização do Método de Avaliação de Risco Incêndio Hospitalar (MARIH), o projeto da edificação hospitalar de grande porte tenha a área de segurança contra incêndio desenvolvida desde as primeiras fases do projeto, garantindo um nível adequado de segurança à edificação de acordo com os riscos envolvidos em um hospital.

Os dez critérios propostos no método foram pensados como um "cenário de incêndio", e formulados tendo como objetivo a identificação e análise dos principais riscos de incêndio que uma edificação hospitalar pode vir a ter.

Entende-se aqui como "cenário de incêndio" o conjunto de condições que define o desenvolvimento do fogo, o alastramento dos produtos de combustão por todo o edifício ou parte dele, a reação das pessoas ao incêndio, e os efeitos dos produtos da combustão. $O$ cenário de um incêndio define as condições que 
o projeto proposto deve observar ao atender as metas de segurança contra incêndio. As condições típicas incluem características dos combustíveis, fontes de ignição, ventilação, características do edifício, e o local e as características dos ocupantes (NATIONAL..., 2009, p. 31).

Os cenários de incêndio são formulados para avaliar os projetos propostos nos códigos com base em desempenho fundamentados em análises de risco quantitativas. O código NFPA - 101: Life Safety Code (NATIONAL..., 2009), no capítulo 5, propõe oito tipos de cenários nos quais os projetos devem ser avaliados. O método proposto por este trabalho, entretanto, é baseado na metodologia de análise de risco qualitativa. Assim sendo, algumas condições (tais como a quantidade de fumaça produzida ou a quantidade de material combustível de um dado ambiente) avaliadas nos cenários de incêndio propostos pelo código NFPA através de mensuração, no MARIH são avaliadas dentro do cenário de incêndio como componentes desse cenário sem mensuração quantitativa.

Isso é facilmente exemplificado no critério sobrevivência externa (Sx). Nesse critério, deve-se avaliar a possibilidade de os ocupantes dos locais adjacentes à área propriamente analisada abandonarem o local sem grandes prejuízos à sua integridade física, uma vez consolidado o incêndio. Considerou-se para a avaliação o potencial de produção e o potencial de deslocamento de fumaça, gases tóxicos e fogo, bem como a não contenção do incêndio na área de início do incêndio.

Não é possível mensurar a quantidade de fumaça no ambiente ou a quantidade de fumaça alastrada para áreas adjacentes; entretanto, através das notas atribuídas a outros critérios como o critério carga incêndio (Ci), pode-se fazer uma avaliação qualitativa de tais condições.

Cada critério do MARIH foi formulado tendo em vista um tipo de cenário de incêndio específico, o que leva à identificação dos principais riscos do dado, cenário. A atribuição da pontuação leva à análise de tais riscos de acordo com o cenário proposto. E, finalmente, o cálculo do índice Evolução de Risco de Incêndio (ERI) e sua classificação indicam os principais danos que tais riscos podem causar no cenário em questão. A partir do processo de identificação e análise dos riscos e da classificação dos danos causados pelos riscos, é possível estabelecer medidas de controle adequadas para tratar tais riscos e suas conseqüências.

Espera-se, então, que o Método de Avaliação de Risco Incêndio Hospitalar (MARIH) e sua aplicação sejam utilizados como uma ferramenta no projeto, elevando o nível de segurança contra incêndio nas edificações hospitalares e demonstrando aos projetistas e aos empreendedores a importância da segurança contra incêndio dentro desse processo.

De certa forma, o MARIH - independentemente de sua aplicação - pode ajudar na conscientização dos projetistas quanto a problemática da segurança contra incêndio nas edificações de grande porte e complexidade. 


\section{REFERÊNCIAS}

AGÊNCIA NACIONAL DE VIGILÂNCIA SANITÁRIA - ANVISA. Resolução RDC no 50, de 21 de fevereiro de 2002.

Regulamento Técnico para planejamento, programação, elaboração e avaliação de projetos físicos de estabelecimentos assistenciais de saúde. Diário Oficial da República Federativa do Brasil, Brasília, DF, fev. 2002.

\section{ASSOCIAÇÃO BRASILEIRA DE \\ ESCRITÓRIOS DE ARQUITETURA - \\ ASBEA. Manual de Escopo de Projetos \\ de Serviços de Arquitetura e}

Urbanismo. São Paulo: ASBEA, 2010.

\section{ASSOCIAÇÃO BRASILEIRA DE NORMAS}

TÉCNICAS - ABNT. NBR 13.531:

Elaboração de projetos de edificações -

Atividades técnicas. Rio de Janeiro: ABNT, 1995.

\section{NATIONAL FIRE PROTECTION} ASSOCIATION. Life Safety Code (NFPA 101). Quincy: National Fire Protection Association, 2009
SÃO PAULO (Estado). Decreto Estadual no 56.819, de 10 de março de 2011. Institui o Regulamento de Segurança contra incêndio das edificações e áreas de risco no Estado de São Paulo e estabelece outras providências. Diário Oficial do Estado de São Paulo, São Paulo, mar. 2011.

SÃO PAULO (Município). Lei Municipal no 11.228, de 25 de junho de 1992.

Estabelece o Código de Obras e Edificações e dá outras providências.

Diário Oficial da Cidade de São Paulo, São Paulo, jun. 1992.

VENEZIA, A. P. P. G. Avaliação de risco de incêndio para edificações hospitalares de grande porte - uma proposta de método qualitativo para análise de projeto. 2012. Tese (Doutorado)-Faculdade de Arquitetura e Urbanismo, Universidade de São Paulo, São Paulo, 2012.

\footnotetext{
Correspondência

Adriana Galhano Venezia, adriana_galhano@uol.com.br

Rosária Ono,rosaria@usp.br
} 